\title{
Lung Cancer pTX TNM Finding v8
}

National Cancer Institute

\section{Source}

National Cancer Institute. Lung Cancer pTX TNM Finding v8. NCI Thesaurus. Code C136445.

Lung cancer in which the primary tumor cannot be assessed. (from AJCC 8th Ed.) 